\title{
¿QUÉ FUE DEL HOMBRE, ENTRE EL SENTIDO Y EL DESBORDAMIENTO DEL LENGUAJE DE LA FE? APROXIMACIONES DESDE PAUL RICEUR
}

\author{
María Belén Tell* \\ doi:10.11144/Javeriana.uph31-63.hsdl
}

\begin{abstract}
RESUMEN
El presente escrito aborda dos cuestiones centrales: la primera presenta, escuetamente, dos etapas del despliegue antropológico de Paul Ricœur, como un esfuerzo por pensar al hombre con una lógica renovada. La segunda enuncia que en tal recorrido filosófico se inserta un plus de sentido en el lenguaje mismo de la fe, que acompaña el propio desarrollo antropológico, y que a su vez desborda y contiene la tarea filosófica específica, aclarando que tal cometido excede los propósitos explícitos del autor francés. En otros términos, pretende tan solo esbozar un "gesto de apertura" de la filosofía contemporánea que, aceptando su heredad, también asume renovados matices, honduras y alcances, permitiéndole a la labor filosófica y al propio ser humano, ir más allá de sí mismos.
\end{abstract}

Palabras clave: antropología hermenéutica; Ricœur; sentido; lenguaje religioso; fe

\footnotetext{
*Universidad Santo Tomás, Bogotá, Colombia.

Para citar este artículo: Tell, M.B. (2014). ¿Qué fue del hombre, entre el sentido y el desbordamiento de la fe? Aproximaciones desde Paul Ricœur. Universitas Philosophica, 31(63), pp. 213-234, ISSN 0120-5323, ISSN en línea 2346-2426, doi: 10.11144/Javeriana. uph31-63.hsdl
} 


\title{
WHAT ABOUT HUMAN BEING, BETWEEN MEANING AND LANGUAGE OF FAITH OVERFLOW? INSIGHTS FROM PAUL RICQEUR
}

\author{
María Belén Tell
}

\begin{abstract}
This paper addresses two central issues: the first one briefly presents two stages of anthropological development of Paul Ricœur's anthropologic deployment, as an effort to think human being with a renewed logic. The second one states that in such philosophical journey a plus of meaning is inserted into the language of faith which accompanies the anthropological development itself and, in turn, exceeds and contains the philosophical specific task, and also makes clear how such an assignment exceeds the explicit aims of the French author. In other words, this paper only seeks to outline a 'gesture of openness' in contemporary philosophy, accepting its heritage, and assuming renewed hues, deeps and scopes, allowing the philosophical work and human being go beyond themselves.
\end{abstract}

Key words: hermeneutic anthropology; Ricœur; meaning; religious language; faith 
(...) El hilo se ha perdido; el laberinto se ha perdido también. Ahora ni siquiera sabemos si nos rodea un laberinto, un secreto cosmos, o un caos azaroso. Nuestro hermoso deber es imaginar que hay un laberinto y un hilo. Nunca daremos con el hilo; acaso lo encontramos y lo perdemos en un acto de fe, en una cadencia, en el sueño, en las palabras que se llaman Filosofia o en la mera y sencilla felicidad. (Borges, 1996, p. 477)

\section{Presentación}

EL HILO AL QUE HACE REFERENCIA EL EPÍGRAFE recae precisamente sobre la cuestión del sentido. Por lo tanto, si Borges insinúa la pérdida del sentido en nuestro contexto contemporáneo, si Weber también ya nos había advertido sobre el presente desencantamiento del mundo actual, cabe preguntarse ¿cómo "recuperar", entonces, o desde dónde reasumir la cuestión del sentido? En otras palabras, ¿tiene aún hoy la filosofía algún espacio y algún medio para seguir preguntando y problematizando con sentido, orientados por la convicción de que la filosofía no implica un mero grupo de letras o palabras, como parece indicar el poema de Borges? En suma, ¿cómo seguir filosofando con sentido, siendo fieles a un método y a la búsqueda auténtica de la verdad?

En efecto, luego del «ego cogito» cartesiano, del «no-sujeto» nietzscheano, del «desencantamiento del mundo» denunciado por Weber, así como de los genocidios y totalitarismos contemporáneos, luego de la lógica de opuestos moderna y tardo-moderna, y de los reduccionismos científicos y filosóficos aún hoy vigentes, corresponde meditar sobre el interrogante: ¿qué fue del hombre? Y, por lo mismo, ¿cabe en la actualidad algún nuevo "pensamiento" que invite a una renovada lógica, una nueva lógica respecto de la comprensión del ser humano? Es más, tales cuestionamientos admiten otras tres preguntas que no pueden deslindarse a la hora de pensar este problema, a saber: ¿qué es el hombre?, ¿quién es cada ser humano?, y ¿dónde está hoy el hombre? Esta última inquietud nos arrima, nuevamente, al asunto fundamental del que partimos: el sentido. A este respecto, citamos unas palabras de la célebre obra de Maurice Blondel, L'Action, de 1893:

¿Sí o no? ¿Tiene la vida humana un sentido y el hombre un destino? Yo actúo, pero sin saber siquiera en qué consiste la acción, sin haber deseado vivir, sin conocer exactamente ni quién soy, ni siquiera si soy. Oigo decir 
que esta apariencia de ser que se agita en mí, que estas acciones leves y fugaces como sombras llevan en sí un peso eterno de responsabilidad, y que no puedo comprar la nada ni siquiera a precio de sangre, porque para mí la nada ya no existe. ¡Estaría entonces condenado a la vida, condenado a la muerte, condenado a la eternidad! Pero ¿cómo y con qué derecho puede ser así, si yo ni lo he sabido ni lo he querido?

(...) El problema es inevitable. El hombre lo resuelve inevitablemente, y esta solución, verdadera o falsa, pero voluntaria y al mismo tiempo necesaria, cada uno la lleva en sus propias acciones. (...) Es bueno proponer al hombre todas las exigencias de la vida, toda la plenitud oculta en sus obras, para reforzar en él el coraje de actuar con la fuerza del que afirma y del que cree. (Blondel, 1973, pp. VII-VIII)

Este pasaje nos invita a pensar una gran cantidad de conceptos y temas, pero detengámonos en cinco nociones que consideramos capitales para iluminar el recorrido en torno a los cuestionamientos precedentes, tales conceptos son: sentido ${ }^{1}$, quién soy, acción, exigencias de la vida y fuerza de afirmar y de creer. Para procurar ir dando respuesta a nuestra problemática, intentaremos hilar estas nociones a través de algunos lineamientos de la obra del filósofo Paul Ricœur. Nos acercamos a este pensador a propósito de este tema porque él concibe a la filosofía como antropología (Ricœur, 1995, pp. 226-227), de modo que todo su espíritu e intento filosófico primordial radicó en meditar sobre el hombre, así como en valorar todas las exigencias y alcances propios de su existencia, y en esta dirección, por qué no, restaurar (restaurer) un renovado "humanismo".

El propósito del presente escrito, por tanto, radica en abordar dos cuestiones centrales: la primera presentará, escuetamente, dos etapas del despliegue antropológico ricœuriano, como posible esfuerzo por pensar al hombre en una lógica renovada. En segunda instancia, se pretende enunciar que en tal recorrido filosófico se inserta un plus de sentido en el lenguaje de la fe, que acompaña el propio desarrollo antropológico, y que a su vez desborda y contiene la tarea filosófica específica, aclarando que tal cometido excede los propósitos explícitos del autor francés. En otros términos, procuraremos tan

\footnotetext{
${ }^{1}$ Es importante señalar que la noción de "sentido" la utilizaremos con un doble aspecto, por un lado, en tanto lenguaje y método gnoseo-epistemológico filosófico que permite decir algo con sentido sobre el hombre; por otro, como la búsqueda constitutiva de sentido por parte del ser humano en nuestro contexto contemporáneo.
} 
solo esbozar un posible "gesto de apertura" de la filosofía contemporánea, que aceptando sus heredades también asume renovados matices, honduras y alcances, permitiéndole así a la labor filosófica, y al propio ser humano, ir más allá de sí mismos.

\section{2. ¿Qué es el hombre? Rodeo en torno a Le Volontaire et l'Involontaire (VI) y a L'Homme faillible (HF) en Finitude et Culpabilité (FC)}

EN EL ITINERARIO ANTROPOLÓGICO DE RICEUR se observa que en la primera etapa descriptiva reflexivo-fenomenológica, su filosofía de la voluntad no se inicia en una "conciencia pura" sin más, o bien en un "idealismo fenomenológico" de corte husserliano (Ricœur, 1989, p. 69; Aranzueque, 1997, pp. 26-36), sino que está sustentada en un cogito que no tiene ni la primera ni la última palabra, y que además está herido (blessé) - no quebrado (brisé) sino heridoy que se "realiza" en la acción. Por consiguiente, en dicho contexto se presenta al hombre como una dualidad entre conciencia y cuerpo, la cual, precisamente, no encuentra su reconciliación en el pensamiento sino que ya está experimentada en el seno de la "subjetividad" del individuo mismo, como adherencia vinculante entre el pensamiento y la afectividad. Vale decir, existe una reciprocidad entre los dos polos: el yo-cuerpo y el yo-sujeto del afecto. Es una sola la experiencia del yo-integral (intégral), como cogito corporal. La conformidad del cogito y su experiencia se da en unidad, pero se manifiesta en una cierta multiplicidad que la estructura voluntaria de la decisión clarifica.

La condición humana implica, así, un misterio en cuanto cogito encarnado, puesto que el sujeto está provisto, por un lado, de estructuras cognitivo-volitivas y, por otro, de necesidades biológico-físico-naturales. Al plantearse un hiato o espacio en suspenso entre los estímulos y las necesidades del cuerpo, del entorno y la respuesta de cada agente, se permite convertir la necesidad en un motivo de acción, siempre que esta no se halle automatizada inevitablemente en su respuesta (Ricœur, 1950, pp. 90-91). La necesidad puede leerse en una doble coordenada: como falta o bien como razón de obrar. Y es justamente en esta experiencia límite, y en este requerimiento de articular constantemente estos aspectos estructurales, donde se juega la humanidad del hombre, a diferencia del resto de las especies de la naturaleza. Ricœur procura desentrañar la compleja tensión y paradoja que implica el existir humano como voluntario libre y, al mismo tiempo, pasivo y padecido. 
Asimismo, la intención de fondo radica en contrarrestar esta ruptura y reconciliación constante con la necesidad de articulación e integración, que es primordial como existenciario antropológico originario ${ }^{2}$.

Se deberá asumir primeramente este planteo de la decisión/ determinación de sí-mismo, consintiendo a lo no elegido y afirmándose responsable y libremente en la realidad, para valorar incluso los alcances del concepto de attestation $^{3}$ posterior, desarrollado en SMA (Ricœur, 1990, p. $35)$. Una inquietud al respecto reside, entonces, en el modo en que el sujeto se constituye, se determina, trata de sortear sus tensiones en un sí definido, en una integridad vital. En orden a esto, el autor francés sostiene que el individuo se hace unidad concreta, viviente y actual en la propia acción, en la que se va definiendo la existencia y se eluden sus arraigadas resistencias, o bien en la decisión puesta en práctica: "en este instante de elección (choix), yo vengo a mí (je viens à moi), procedo de las tinieblas interiores, surjo [yomismo] (surgis moi-même), ex-isto (j'ex-siste)" (Ricœur, 1950, p. 163).

Determinar-se, entonces, implica que los motivos corporales, las estructuras involuntarias no elegidas, inclinen y ejerzan una tendencia, un condicionamiento pero sin necesidad, sin determinismo ni obligación per se (Ricœur, 1950, p. 177). La paradoja humana radica en este núcleo donde la conciencia no es completamente "pura" ni unificada en su totalidad. Esta conciencia (conscience), este "cogito blessé" -conciencia herida-, no constituye ni el principio, ni el horizonte último en el conocimiento del mundo, lo que sí incorpora son valores a partir de una historia concreta al ser "capaz" de elegir, pero dentro de ciertos límites. En otras palabras, la totalidad de la experiencia humana le desborda -en cuanto receptividad/ pasividad-, ya que no puede pensar ni elegir de modo "absoluto". Los existenciarios involuntarios -absolutos y relativos- (Ricœur, 1950, pp.

\footnotetext{
${ }^{2}$ A partir de esta ontología paradójica (ontologie paradoxale) se jugará la comprensión del quien en su doble particularidad dual y recíproca, así como la necesidad de integración de los distintos aspectos humanos en un cogito integral, en un cuerpo-reflexivo-práctico.

${ }^{3}$ El concepto de "atestación" (attestation)-atestar-atestado, posee un significado técnico en la obra ricœuriana, distinguiéndose totalmente de su sentido coloquial en español, en cuanto "colmar o llenar" respectivamente. Dicho vocablo podría definirse técnicamente, entonces, como la seguridad, la garantía o la "certeza" existencial-superando toda sospecha de tradición cartesiana y/o nietzscheana-, que la ipseidad (identidad narrativa) hace de sí misma, en tanto afirmación ontológica.
} 
394, 395) constituyen, así, la condición recíproca de la acción y del existir como tal, en cuanto que "son el lugar de mi responsabilidad (le lieu de ma responsabilité)" (Ricœur, 1950, p. 119). En la acción se articula lo que en el cogito queda dividido, en los actos se concilian todos los aspectos del sujeto y así se describe el modo como opera la existencia humana, en un plano fenomenológico aún. En la acción, el cuerpo y la conciencia se enlazan para forjar la afirmación del individuo como "capaz de" frente a otro. En la acción el "yo" existe, se da integrado, vinculando lo real al pensamiento por la reflexión y el movimiento (Ricœur, 1950, p. 234) consentido y decidido.

Otra de las cuestiones centrales reside en que el cogito integral se alza, originariamente, a partir de una réceptivité total y de una pasividad absoluta, llámese nacimiento, cuerpo, emociones y sensaciones, progenitores, cultura, historia, entre otras. Y es desde esta receptividad y suelo o lugar limitado y condicionado, que el individuo comienza el despliegue de su existir responsable y reflexivo. Es a partir de aquellas receptividades pasivas que cada cual tendrá que forjar su deliberación, elección y decisión para una acción concreta y libre.

En efecto, frente a la paradoja de la existencia aparecen estas capacidades del proyectar, decidir, obrar y consentir que se ejercen en un horizonte de receptividades pasivas no elegidas, como son el nacimiento, la organización vital, el crecimiento, el cuerpo propio y, con él, el inconsciente y el carácter, la conciencia y los otros, como la familia y la cultura, que ofician de suelo de la existencia, de la acción y del mutuo y libre re-conocimiento. Dado que la realidad humana acontece como una unidad vital, pero al mismo tiempo sumergida en una dualidad "dramática" entre el querer de la voluntad y la espontaneidad biológico-corporal (Ricœur, 1950, p. 215), no solo habrá una tensión naciente entre estas dos estructuras fundamentales antropológicas, sino que habrá siempre que articular también este conflicto entre los poderes y las pasividades-receptividades, entre el deseo (désir) (Ricœur, 1950, p. 97) y la razón, entre aquello que abre la experiencia humana y su situación concreta y limitada, cultural e histórica.

El individuo existe como unidad entre la existencia querida y la pasiva padecida (subie), entre la espontaneidad de la vida y la libertad responsable: "j'existe-un" (Ricoœr, 1950, p. 387). Y es posible esta unidad si se establece una reconciliación reflexivo-práctica entre las necesidades y los poderes, entre los motivos y órganos vitales con el querer encarnado. Todas las 
estructuras involuntarias relativas y absolutas, como la vida, constituyen el suelo y lugar de la voluntad y de la conciencia misma (Ricoœr, 1950, p. 395). El consentimiento articula, entonces, el límite con la conciencia, se acepta así lo inconsciente, el carácter y la propia necesidad, teniendo el sujeto que oficiar de árbitro entre las estructuras fundamentales en tensión de instancias activas y pasivo-receptivas.

En este sentido, en el transcurso de toda la obra ricœuriana se intenta acercar, por rodeos fenomenológico-hermenéuticos y reflexivo-existenciales duales, dialécticos y en desproporción, al centro del cuestionamiento de ¿qué-quién es el hombre? La respuesta al final se instalará en el concepto de una ipseidad narrativa, frágil, pero que se "atesta" en sus capacidades. Y será en este contexto que Ricœur buscó, ya en su primera etapa de despliegue antropológico, aquello que constituye "l'unité d'une personne en soi et pour soi" (la unidad de una persona en sí y para sí), así como una "philosophie de la personne" (filosofía de la persona) (Ricœur, 1992, pp. 195ss; 1960, p. 63). Empero, no será todavía en esta proyección pura donde se encontrará dicha "richesse substantielle" (riqueza sustancial).

La persona configura esa bisagra que intentará lograr una "síntesis" entre los dos polos fundamentales en desproporción, a saber: el origen recibidopasivo y el horizonte infinito de la experiencia de totalidad humana. En este sentido, el filósofo francés no solo abordó la condición de la existencia en términos de polaridad fundamental entre lo voluntario e involuntario, sino que también la presentó como una dualidad entre lo finito e infinito repitiendo, una vez más, la paradoja en tensión entre el poder-de y el recibir (Ricœur, 1960, pp. 52-53), entre la actividad y el padecer, entre la capacidad y la pasividad respectivamente.

La paradójica condición humana radica en que el hombre mismo es límite, es mediador de sí-mismo entre su afirmación originaria y su diferencia existencial -al riesgo de negarse en ella-, persiguiéndole el desafío de existir como límite. Consideramos, no obstante, que en la figura de la atestación -en la cual el autor consumará sus alcances antropológicos- aparecerán otros elementos que complejizan, enriquecen y exceden este planteamiento respecto de la dialéctica entre el "deseo de ser" y "lo que apenas se es", no resolviendo ni eliminado, definitivamente, el conflicto interior ni la desproporción intrínseca a la existencia humana, pero sí proponiendo un 
novedoso camino hermenéutico-narrativo para hacer-se-cargo-de-sí y asumir-se como tal, en cuanto ser humano frágil pero al tiempo "oyente $y$ en-relación".

La persona constituye, por tanto, la alegría de un sí que se afirma, pero de manera finita, limitada; es un mediador frágil de sí-mismo que revela una falla, grieta o inadecuación profunda dentro de sí, que solicita un esfuerzo, un proceso y una tarea para articular los extremos, finitos e infinitos, en desproporción. Lo relevante, en el planteo ricœuriano, es que el hombre mismo se convierte, en primer lugar, en mediador de sí mismo por las "desproporciones" que alberga, antes de poder superar o articular, en segunda instancia, las que están fuera de él, o que vienen del mundo exterior.

La síntesis entre la perspectiva y el decir, oficiada por la "cosa" en el plano teórico, se plasma en la "obra" en el plano práctico, entre la materia y el sentido. Sin embargo, a pesar de que el hombre en sus obras logre conciliar exigencia y contingencia, sigue siendo, en sí y para sí, un paradójico desgarramiento. El sujeto establece permanentemente mediaciones -teóricas, prácticas y afectivas- de su "yo" y de su cuerpo a su "sí-mismo" integral, a través de articulaciones, asumiendo las dualidades y polaridades, dentro de sí, y a través de mediaciones fuera de sí.

La acción, en consecuencia, depende de un "qui" (quién) la realice y la sostenga desde sí, dado que el conflicto (conflit) que continúa abierto y "no-coincidente" consigo mismo es el que se opera en el sentir, en un "corazón" humano dividido entre la exigencia que plantea y lo que en su fragilidad "apenas puede". Y es por esta discordancia u oposición que no se encuentra o reúne totalmente en ninguna síntesis, sino que el hombre mismo tiene que oficiar de síntesis y mixto (mixte) permanente para sí mismo, en un "quién" consciente y reflexivo que dé respuestas para sí y para el otro, "dialectizando" concretamente los polos fundamentales de su desproporción originaria (Ricœur, 1960, pp. 156-157).

La dialéctica entre la afirmación y la diferencia, entre la finitud y la infinitud, puede articularse por la presencia reflexivo-existencial de un quien que la sustente. El conflicto o desproporción interior no se puede disolver, pero sí conocer, pensar, decir, interpretar, proyectar pero, sobre todo, asumir en un "quien" libre que armoniza bíos y lógos. Con todo, la síntesis oficiada 
por el hombre es falible y lábil; siempre se encontrará afligido en un conflicto entre la afirmación originaria y la diferencia existencial, entre el désir d'être... (deseo de ser) y lo que a penas y limitadamente se es. Las exigencias que ponen la razón, la voluntad y el sentimiento, rebasan y exceden las posibilidades finitas humanas; sin embargo, el mixto y mezcla que combina y articula el hombre transforma, asimismo, esta paradoja en posibilidad y capacidad de disponer un soi-capable (sí-mismo capaz) de responsabilizarse y de respetar-se-a-sí y a los otros-como-sí.

\section{3. ¿Quién es el soi-même? A propósito de Soi-même comme} un autre (SMA)

LA SEGUNDA ETAPA DEL RODEO DEL QUI -QUÉ/QUiÉN- en la antropología ricœeuriana, reside en la hermenéutica de la identidad personal-narrativa. Encontramos, de este modo, en ambas etapas antropológicas del filósofo, un cruce entre dos interrogantes -ya enunciados al comienzo-, que también permanecen en tensión y mediación, a saber: ¿qué es el hombre? y ¿quién soy yo? Y la diferencia entre ambos cuestionamientos radica en que el primero hace referencia a lo genérico y universal, mientras que el segundo se remite a lo singular y único de cada individuo. Las estructuras de comprensión son las mismas para todos, pero el alcance de apropiación de las respuestas es diferente, dado que en $V I$ y en $H F$ la pregunta se acercaba al ser del quién humano, al ser del hombre, de todo hombre. Mientras que en $S M A$, la respuesta asume una sutileza más honda, dado que la identidad del quién no responde por el hombre en general solamente, sino por aquellas estructuras universales y fundamentales comunes, pero que se hacen "únicas e irrepetibles" en cada quién con nombre propio respectivamente. En otras palabras, el plano ontológico es igual en todos, pero el plano dinámicoexistencial-biográfico es singular e individual.

Hemos pasado de una pura reflexión descriptiva de las estructuras biocorporales y de las que exige la voluntad, a la desproporción y fragilidad de la persona, hasta llegar a estos criterios narrativo-temporales y hermenéuticos en los cuales interviene una nueva relación: la del texto y la imaginación. La auto-comprensión del qui que se inició formal y descriptivamente, pasa ahora por esta instancia narrativa de inteligencia creativa -ya avizorada también en la "imaginación trascendental" en $F C$-para poder culminar, más adelante, con la ipseidad-atestación, que permitirá configurar un soi-même "con la fuerza de afirmar y de creer (affirmer et de croire)" (Blondel, 1973, p. VIII). 
Siguiendo con nuestro hilo argumentativo, nos encontramos en esta etapa hermenéutica con el primer concepto: narratividad (narrativité), que permite indicar la permanencia del nombre propio, y fundamenta al agente de la acción como tal al ser designado por su nombre como el mismo-él mismo a lo largo de toda una vida.

El soi, en dicho rodeo hermenéutico-temporal, aparece constituido a la vez como lector y como escritor de su propia vida, y no hace referencia ni a un yo, ni un tú, ni una comunicación intersubjetiva, sino a una narración en donde él-mismo reclama lo-otro como sí-mismo narrado y desplegado en el tiempo. De este modo, la relación entre el sujeto y su obra acontece en el relato unificando la totalidad de su vida, atravesada por el tiempo como nexo. La definición del qui de la acción y de la narración se vincula, así, a las nociones de lector, escritor, personaje y agente de la narración y de la vida.

En este sentido, Ricœur (1990, p. 175) establece parámetros precisos de enlace que vinculan la categoría de persona (personne) con la de personaje, por ej.: la de ser ambas un "cuerpo", mediante el cual introduce cambios en el mundo y acciones interviniendo en el curso de las cosas. Lo propio de la persona (Ricœur, 1992, p. 198) -de la cual depende la acción- es que posee una historia, es "su propia historia" (sont leur propre histoire) (Ricoeur, 1990, p. 137). Ricœur no sólo se vale de esta noción para profundizar en la identidad personal y narrativa, sino también de otros dos términos como son el de mismidad e ipseidad, y en medio de ambos polos se encuentra la narratividad para articularlos. Por lo que la identidad de una persona está configurada por los poderes-de la decisión (Ricoeur, 1950, p. 41) y de la narración, y por la pasividad del carácter-ídem, de manera que la ipseidad del sí es tal en cuanto sí-mismo, al tiempo que asumiendo simultánea y constitutivamente su otredad-alteridad.

La identidad personal-narrativa es representante también de las estructuras receptivo-originarias fundamentales activo-capaces/pasivas en tensión-mediación, a saber: voluntario/involuntario, conciencia/ cuerpo, finitud/infinitud, carácter/felicidad, afirmación/diferencia, entre otras, porque articula los polos de la mismidad e ipseidad del quién en su condición humana mixta. Dicha identidad personal-narrativa radica en el poder-permanecer, mediante una palabra, acción o moción voluntaria, frente a otro que re-clama, a pesar de los cambios que se sufren en el tiempo, de las contradicciones y de las estructuras en tensión -carácter y felicidad, por ejemplo-propias del hombre. 
El relato, al narrativizar, le brinda movimiento dinámico y temporal al carácter, que de lo contrario quedaría neutralizado por las tendencias biológicas innatas, por adquirir involuntariamente ciertas disposiciones, o bien por sedimentar identificaciones-con. Es, entonces, en el intercambio de experiencias -en tanto ejercicio popular de la sabiduría práctica (sagesse pratique)-(Ricœur, 1990, pp. 204/406), que opera el relato en cuanto arte de narrar (Ricœur, 1990, p. 193), donde las acciones o mociones voluntarias y sus agentes de acción son evaluados, juzgados para bien o para mal, aprobando o censurando-se (Ricœur, 1990, p. 194). En este sentido, la responsabilidad es, nuevamente, co-constitutiva de la noción de identidad narrativa, y el ser humano se define como persona en su responsabilidad en cuanto componente ético originario (Ricœur, 1960, p. 158).

\section{Hombre/mujer: ¿Dónde estás?}

Sin ÁNIMO DE INMISCUIRNOS EN ESTE APARTADO en el desarrollo ético-moral del quien, dejando también en claro que para cada tema presentado se requeriría dedicar un trabajo específico para precisar sus alcances, y señalando honestamente que en estas pocas páginas no se pueden agotar ni mencionar con exhaustividad todos los argumentos al respecto, nos atrevemos de todos modos a resaltar a partir de este punto, que consideramos como de inflexión en el recorrido antropológico ricœuriano, una arista que generalmente se la aborda en un sentido ético-político sin más, pero que nosotros la mostraremos en su relación con el tema del sentido, con un sentido hermenéutico "ampliado", que se va tramando solapadamente en el discurrir filosófico del pensador de Valence.

En efecto, en tal itinerario antropológico la identidad humana radica en su ser-capaz-de responsabilidad, en responder frente a otro, en mantener-se en una palabra o en un acto, en tanto el otro puede contar-con el sí-mismo y este ser responsable-de aquel. El carácter y el poder mantener-se éticamente frente a otro como co-responsable -y no sólo éticamente-, definen el núcleo central de la existencia humana en cuanto identidad narrativa:

« ¿Dónde estás?»(Où es-tu), pregunta planteada por el otro que me solicita (l'autre qui me requiert). (...) «iHeme aquí!» (Me voici!). Respuesta (réponse) que dice el mantenimiento de sí (maintien de soi).

(...) « ¿Quién soy yo [-mismo] (Quién es mi yo) (Qui suis-je, moi), tan versátil (si versatile), para que, sin embargo, cuentes conmigo (tu comptes sur moi)?». (Ricœur, 1990, p. 195) 
En este pasaje comienza a confirmarse el punto central del largo rodeo hermenéutico del quién resumido en las preguntas: ¿dónde estás?, ¿quién soy yo, para que allende la propia versatilidad, la diferencia existencial, la falibilidad y desproporción, el otro cuente con el soi? En tales interrogantes reside el movimiento dialéctico de la ipseidad-del-si y del otro -alteridad pasiva-, en el que el primero se vuelve disponible para el autre que irrumpe en el soi pudiendo quebrar su cierre total sobre sí-mismo (Ricoeur, 1990, p. 198). La ipseidad en la hermenéutica del soi ricœuriana se determina, de este modo, en dos momentos: en el paso por el "contraste" entre ídem e ipse, o entre mismidad, o carácter, e ipseidad, o mantenimiento de sí; y en la dialéctica entre la ipseidad y las distintas alteridades que padece - pathos-en su relación (Ricœur, 1990, p. 345).

Lo-otro-distinto-de-sí y el-otro inter-actúan en dos instancias formando parte de la constitución de la ipseidad del sí en un doble aspecto: a) siendo parte de la cultura, valores, instituciones en las cuales el carácter pasivo se reconoce e identifica-con y va sedimentando sus disposiciones; y en el mantenimiento de sí-mismo en la promesa, ya que la capacidad de permanecer es siempre una responsabilidad ante alguien, ante otro que reclama el estar presente del soi. b) Como alteridad o pasividad-receptiva, en orden a la cual la ipseidad tiene que ir realizando distintas y constantes relaciones y dialécticas entre la identidad como ipseidad y las diferentes instancias de alteridad, que también co-constituyen la afirmación del soi, en tanto pasividades recibidas a las que se tienen que consentir, comprender e interpretar narrándolas con un sentido.

Sin ahondar aquí en la cuestión de la alteridad-atestación, y retomando el texto citado líneas arriba e hilándolo con estas ulteriores afirmaciones, cabe cuestionarse: ¿Quién profiere, en última instancia, la pregunta "¿dónde estás?"?, para que el "soi" conteste "heme aquí", ¿qué Alteridad, o Realidadreceptiva, que co-constituye también el camino de la afirmación del soi, permite a su vez narrar con sentido? Consideramos que pensar al hombre en una lógica renovada residiría precisamente en esta apelación a ciertas formulaciones que desbordan el lenguaje y conceptualización filosófica, y lo colocan en una apertura de sentido que sigue "dilatando el pensar". Dicha restauración fue suscitándose a través de todo el recorrido antropológico ricœuriano analizado, y permitió a su vez imbricar y articular con un sentido nuevo las cinco nociones relevantes de las cuales partimos, como son la acción, el qué/quién soy, las exigencias receptivas activo/pasivas de la existencia, el sentido y la fuerza de afirmar y de creer. Sin embargo, pareciera 
ser que estas dos últimas nociones no quedaran del todo evidenciadas en este trazado antropológico, empero, las expresiones recién aludidas de "¿dónde estás?" y de "heme aquí", revisten un origen, una hondura y ciertos alcances que le permiten "generosamente" a la hermenéutica filosófica abrir su reflexión ubicándola en el "entre del sentido", ya que aquella no constituye ni la primera ni la última palabra.

En efecto, aquello que permitiría seguir hablando del hombre y ensanchar el horizonte antropológico hacia la restauración de un renovado "humanismo" en la filosofía contemporánea, radicaría en la apelación a expresiones que admiten un plus de sentido no sólo fenomenológico-hermenéutico sino también existencial, ampliando el discurso antropológico de las estructuras voluntarias e involuntarias, de la desproporción entre finitud e infinitud, de la identidad narrativa y atestación, en un lenguaje y sentido nuevos sobre lo humano, en donde el hombre también re-encuentre su sentido reconocido, a su vez, en la estructura fundamental misma de su existencia.

Con todo, lo que aquí se manifiesta es el vínculo fundamental que atraviesa la identidad humana entre el acto de llamar y el de responder a ese llamado, y que además define al hombre como ser "oyente y en-relación". Dicha relación aparece traslucida en la obra ricœuriana, por ejemplo, a través de esas dos formulaciones del ¿dónde estás? y del "Heme aquí" (Me voici!) que supone a alguien otro, dado que el acusativo implica la relación entre la primera y la segunda-tercera persona en el lenguaje coloquial.

En definitiva, la pregunta ¿qué/quién es el hombre? nos remitió a la pregunta ¿dónde estás? Y la respuesta a tal interrogante del "heme aquí" nos acercó a la exigencia de ampliación de sentido de la propia búsqueda antropológica, situándonos en una realidad en la que se aúnan un discurso pre y supra-racional, pre y meta-filosófico que muestra, viva y activamente con nitidez, un vínculo y plus de sentido que desborda, pero que al mismo tiempo abraza como suelo y horizonte, todo lenguaje, conocimiento filosófico y experiencia personal humana. Y ulteriormente, es en este punto que radicaría la "fuerza de afirmar y de creer", ya que no es posible pensar y conocer al hombre en todos sus alcances, sin la apelación a una lógica y lenguaje que lo coloquen desde su racionalidad, en un sentido más allá del mero análisis filosófico, conectándolo asimismo con su exigencia de "oyente" originaria; en otros términos, colocándolo frente a otro lenguaje: el de la fe. 
Cabe subrayar que las referencias que aparecerán a continuación (2008) y respecto de lo anterior, pertenecen al estudio noveno de las Gifford Lectures $(G L)$ denominado "El sí en el espejo de las escrituras" (Le soi dans le miroir des Écritures), y recogido en el libro Amour et justice (AJ), junto a una conferencia homónima y al estudio X de las GL. El propio Ricœur aclaró, asimismo, que no fueron incluidos deliberadamente esos dos estudios de las $G L$ en $S M A$, para permanecer en la fidelidad a su promesa de no "mezclar" (mêler) lo teológico y lo filosófico (Ricour, 1995, p. 140). Y, si bien en SMA se eliminaron estas dos conferencias "religiosas" finales, sostenemos que el proyecto total y unitario del soi-même apela al binomio de "llamada-preguntallamada", vislumbrándose así un parentesco tácito entre las dos conferencias de las $G L$ y $S M A$, y que a su vez se distingue, allende las diferencias y matices que aparecen en las diversas etapas de la obra de Ricœur, una evidente línea de contigüidad entre una y otra. Es por esta razón que iniciamos la búsqueda sobre el aún incipiente "soi-même", explicitando sucintamente sus rodeos en torno a $V I$ y a $H F$, para luego prolongar el rastro en $S M A$, y ahora poder culminar en lo que sigue con las $G L / A J$ respectivamente.

\section{Desde y hacia el desbordamiento: entre la antropología filosófica y la fe}

PaUl Riceur asume la FORMULACión De LO QUE SERÍA algo así como una experiencia religiosa (expérience religieuse) en tanto:

[S]entimiento de «absoluta dependencia» (sentiment d'absolue dépendance) respecto de una creación (création) que me precede, «inquietud/[cuidado] última/o» (souci ${ }^{4}$ ultime) en el horizonte de todas mis preocupaciones, «confianza incondicional» que espera a pesar de... todo (confiance inconditionnée, qui espère en dépit de... tout). (...) La $\mathrm{fe}^{5}(f o i)$ es, en cuanto tal, un acto (acte) que no se deja reducir a ninguna palabra (parole), a ninguna escritura (écriture). Con este derecho, ella marca el límite de toda hermenéutica, porque está en el origen de toda interpretación (interprétation). (Ricœur, 2008, pp. 52-53)

\footnotetext{
${ }^{4}$ Podría jugarse aquí con el término «souci» y traducirlo no sólo como "inquietud", sino también como cuidado, y como "cuidado último".

${ }^{5} \mathrm{Fe}$ es el nombre que reciben, en la época contemporánea, las definiciones precedentes.
} 
Se perfila claramente que la experiencia religiosa se vincula, aparentemente de un modo clásico, a un sentimiento de dependencia absoluta $^{6}$, a una confianza incondicional y a un horizonte último de las propias preocupaciones $\mathrm{y}$, concomitantemente, la fe constituye un acto irreductible, es un derecho que precede y al tiempo está en el origen de toda interpretación. En consecuencia, podría afirmarse que la fe -al estar en el origen- vendría a iluminar e irradiar a toda posterior interpretación.

Asimismo, en otro pasaje encontramos que:

[L]a experiencia religiosa (expérience religieuse) se articula siempre en un lenguaje que se oye en un sentido cognitivo, práctico o emocional (entende dans un sens cognitif, pratique ou émotionnel). (...) Lo que especifica la fe bíblica (foi biblique) entre todas las configuraciones de lenguaje (configurations langagières) de la experiencia religiosa es la mediación escrituraria (médiation scripturaire) que ha servido como tamiz de interpretación (grille d'interprétation) a la experiencia religiosa propia de los miembros de las comunidades judías y cristianas. (Ricœur, 2008, p. 53)

Aquí surge una sutil precisión que parece distinguir cualquier configuración de lenguaje de la experiencia religiosa con una en particular: la fe bíblica, identificada por su mediación escrituraria y hermenéutica. Tal especificación de la fe es a la que Ricœur se referirá, por lo general, para relacionarla con la filosofía y la crítica. Otro elemento relevante que sobresale del texto radica en que se vincula la experiencia religiosa con una vivencia a nivel teórico, práctico y afectivo mediante un lenguaje que se oye, es decir, la condición existencial en su triple dimensión escucha a través de un cierto lenguaje.

La fe también aparece, en la obra ricœuriana, caracterizada por un rasgo pre-lingüístico y supra-lingüístico en el que se la comprende del siguiente modo:

La fe escapa a la hermenéutica y atestigua que esta última no constituye ni la primera ni la última palabra. Pero la hermenéutica nos recuerda que la fe

\footnotetext{
${ }^{6}$ Esta definición de Ricœur se emparienta con la concepción de Schleiermacher al respecto: "« [L]a dependencia absoluta como protoexperiencia del estar realizado», si bien esta segunda no es «ni un saber ni un obrar, sino una determinación del sentimiento o de la autoconciencia inmediata»" (Von Balthasar, 1999, p. 32).
} 
bíblica no puede separarse de la interpretación que la eleva al lenguaje. La "inquietud última" permanecería muda si no estuviera sostenida por una palabra renovada sin cesar por la interpretación de los signos y los símbolos que, por así decirlo, transmiten esa inquietud a través de los siglos. En cuanto al sentimiento de "dependencia absoluta", sería un débil sentimiento si no correspondiera al proyecto de un ser nuevo que abre nuevas posibilidades a nuestra existencia. La esperanza, o "confianza incondicional”, quedaría vana y vacía si no se apoyara sobre una interpretación renovada sin cesar por acontecimientos-signos atestiguados por las Escrituras, en particular por los relatos de liberación en el Antiguo Testamento y de resurrección en el Nuevo. Son acontecimientos que significan las posibilidades más extremas de nuestra libertad, convirtiéndose para nosotros en Palabra de Dios. Tal es la determinación hermenéutica de la fe bíblica. (Ricœur, 1994, pp. $70-71)^{7}$

Es posible vislumbrar una suerte de dialéctica, en sentido circular, entre la hermenéutica y la fe bíblica, puesto que ambas no pueden separarse dado que la hermenéutica permite expresar, formular y abrir nuevas posibilidades, determinando así a la fe bíblica. Y tales determinaciones permiten de igual manera transmitir en un lenguaje comprensible la fe bíblica, pero teniendo siempre en cuenta que la hermenéutica no constituye ni la primera ni la última palabra. Por tanto, ella estaría en el medio de dos instancias que la preceden y la desbordan: una dependencia absoluta y confianza incondicional, así como una inquietud/cuidado último en cuanto excedente de sentido y no circunscrito a ningún límite humano.

La "fe bíblica es, en el sentido preciso de la palabra, sin conceptos" (Ricœur, 1994, p. 227), es sin conceptos en el sentido filosófico ya que apelará a otro lenguaje de tipo pre o supra-filosófico (Ricœur, 1994, p. 223), “el único recurso es llamar a este lenguaje kerigmático (langage kérygmatique), para decir que es al menos metafórico, pre- o super-metafórico (pré- ou super-métaphorique)" (Ricœur, 2008, p. 56). La importancia hermenéutica del lenguaje pre-supra-metafórico en este contexto hace referencia a que:

[L]a única relación con la realidad (rapport avec la réalité) que importa en un texto poético (texte poétique) (...) es el poder de suscitar (pouvoir de susciter) en el oyente y el lector el deseo de comprenderse él mismo a la luz del Gran Código (désir de se comprendre lui-même à la lumière du Grand

\footnotetext{
${ }^{7}$ Véase, además: Ricœur (1986, p. 146).
} 
Code). (...) En ese momento, el lenguaje, poético en sí (en soi), se torna en kerigma para nosotros (kérygme pour nous). (Ricœur, 2008, pp. 58-59)

Se observa con claridad el punto de inflexión hermenéutico en esta apelación a la comprensión de sí-mismo a través del Gran Código (Ricœur, 1995, p. 238), puesto que el lenguaje poético ${ }^{8}$-que determina dicho Textoprovoca a la imaginación y esta obliga a:

[P]ensar más. La imaginación creadora (l'imagination créatrice) no es otra cosa que este pedido dirigido al pensamiento conceptual (pensée conceptuelle). (...) La metáfora no es viva sólo en que vivifica un lenguaje constituido. La metáfora es viva porque inscribe el impulso de la imaginación en un «pensar más» a nivel del concepto (elle inscrit l'élan de l'imagination dans un "penser plus» au niveau du concept). Esta lucha por el «pensar más», bajo la conducción del «principio vivificante» es el «alma» de la interpretación (c'est cette lutte pour le «penser plus», sous la conduite du «principe vivifiant» qui est l'«âme» de l'interprétation). (Ricœur, 1975, p. 384)

Consideramos que es en este principio vivificante que ambas hermenéuticas -bíblica y filosófica-se encuentran.

A diferencia de la filosofía, la instancia religiosa es:

[U]n momento de adhesión (moment d'adhésion) a una célebre palabra que viene de lo más alto y lejano que yo (réputée venir de plus loin et de plus haut que moi), y esta, en una lectura kerigmática, confesional. Encontramos, pues, en este nivel, la idea de una dependencia o de una sumisión a una palabra anterior (dépendance ou d'une soumission à une parole antérieure), mientras que en la esfera filosófica..., incluso si el mundo de las ideas nos precede es, sin embargo, por un acto crítico (acte critique) que se apropia la reminiscencia que toma el sentido de una preexistencia. (Ricœur, 1995, p. 219)

Lo propio de la filosofía, entonces, es que asume sus nociones, tesis e interpretaciones mediante una apropiación mediatizada por la crítica; en cambio, la actitud religiosa parte de la adhesión a una palabra que la

\footnotetext{
${ }^{8}$ Respecto de juzgar al discurso bíblico como poético constituye un tema que da para otra investigación, lo que sí podemos decir aquí es que el lenguaje bíblico no se reduce en ningún caso al poético, empero ambos comparten algunos rasgos específicos.
} 
precede, a una palabra anunciada y revelada proveniente de lo alto y lejano. Ricœur (1995, p. 228) sostiene, por tanto, que la especificidad de lo religioso "sirve de revestimiento (sert d'enveloppe)" a su organon filosófico, y en este sentido un registro, por turno, reviste o envuelve al otro en un englobe mutuo (englobement mutuel).

En efecto, otra de las referencias a la proximidad entre fe y filosofía reside en que la relación entre ellas "refleja una dialéctica más profunda, a saber, la que existe entre la poética de la existencia y la argumentación del intelecto. Para precisar esta relación tomaré el ejemplo de la dialéctica del amor y de la justicia" (Ricœur, 1994, p. 226). Este pasaje marca un umbral en nuestro escrito, dado que entre las anteriores apelaciones al vínculo entre la fe y la antropología filosófica, en esta sentencia, que expresa una dialéctica más compleja en términos de "poética de la existencia" y de "argumentación del intelecto", se deja entrever una brecha en la medida en que se advertiría un "juego" entre realidad y desbordamiento, entre filosofía y supra-filosofía, entre ética y meta-ética, que continúa invitando así a un pensar más.

Asimismo, para Ricœur, la fe bíblica también implica una respuesta,

$[\mathrm{R}]$ esponder, frente a la palabra de las Escrituras (répondre, face à la parole des Écritures), es corresponder a las proposiciones de sentido surgidas de la donación bíblica (correspondre aux propositions de sens issues $d u$ donné biblique). De ello resulta que la relación entre las dos maneras de responder prueba ser de una complejidad inmensa (complexité immense) que no sabría contener el esquema de la pregunta y de la respuesta (le schéma de la question et de la réponse). (Ricœur, 2008, p. 47)9

En consecuencia, la filosofía y la fe implican un tipo de respuesta diferente; ambas consisten en responder, y al hacerlo de manera heterogénea no se oponen. Por ello, dado que se evita pensar a la fe en tanto estructura de respuesta y a la filosofía en cuanto pregunta, ambas se toman como respuestas, una de cara a un problema racional y la otra frente al Texto bíblico. Empero, de la relación entre ambas respuestas se produjeron tensiones que animaron gran parte de las discusiones del pensamiento occidental, sea que se haya asumido o rechazado la tradición bíblica (Ricœur, 2008, p. 48).

\footnotetext{
${ }^{9} \mathrm{Al}$ respecto, véase: Ricœur, 1990, p. 37.
} 
En los textos recopilados en $F F$ aparece también expresado que responder a una cuestión consiste en resolver un problema, mientras que la respuesta, en cuanto aceptación de fe, implica "responder al llamado del Otro en el sentido religioso..., es decir, corresponder a la concepción de la existencia que ese Otro propone y ofrece como un don. (...) Un problema es lo que nosotros hacemos y formulamos, en filosofía como en matemáticas; por el contrario, un llamado es recibido como no viniendo de nosotros, sino, para el creyente judío o cristiano, de una Palabra recogida en las Escrituras" (Ricœur, 1994, p. 223). Y si bien el binomio fe/antropología filosófica implica una respuesta a lo es en un sentido distinto, ya que la filosofía, tal como el álgebra, propone sus problemas en tanto que los formula y procura resolverlos, mientras que la fe consiste en una respuesta a un llamado recibido, y que claramente no viene de nosotros sino de una Palabra que precede y desborda al lenguaje humano.

Resta indicar que en orden al rastreo del plus de sentido que desborda lo filosófico en la antropología de Ricœur y que se vincula a las formulaciones de fe bíblica y a la estructura de "llamada-pregunta-llamada", es menester puntualizar que en el presente escrito no podemos desarrollar con exhaustividad todas las apelaciones - de toda la obra del autor-a la variedad de expresiones que admiten dicho plus de sentido. Por ende, sugerimos remitirse al estudio desarrollado (Tell, 2013), ya que tal investigación despliega y profundiza con mayor detenimiento y contenido argumentativo nuestro cometido, en tanto "descubrimiento y relación de las fuentes suprafilosóficas como claves para una vivificada comprensión de la antropología de P. Ricceur" 10 .

Por lo tanto, agregamos que la fe es un acto que implica responder afirmativamente a un llamado, a una invitación a corresponder-nos con la concepción de la existencia que ese Otro propone y ofrece como un don. La respuesta filosófica involucra la racionalidad, la crítica y el ingenio, mientras que la respuesta de fe toca toda la existencia, su intimidad, su raíz, su sentido y horizonte último en cuanto que apela a una relación que ese Otro llama a recibir. Dicha relación aparece traslucida en la obra ricœuriana a través

\footnotetext{
${ }^{10}$ En relación con tales temáticas cabe mencionar un libro de próxima aparición (Tell, 2014) titulado: Tras la huella del testimonio. Estudio filosófico sobre los silenciosos alcances de la antropología hermenéutica de Paul Ricour.
} 
de dos formulaciones, entre otras, de hondo contenido bíblico, estas son: el "Heme aquí" (Me voici!) que supone a un otro, dado que el acusativo implica la relación entre la primera y la segunda-tercera persona en el lenguaje coloquial -y ya abordado en los puntos precedentes-; y el "¡Tú Ámame!" (Toi, aime-moi!) (Ricœur, 1990, p. 405), que irradia también una relación pero con el agregado de ser una relación amorosa, un amor que pretende reflejar en la aparente orden o mandamiento imperativo de que lo ¡Amen!, no una exigencia caprichosa o "deberística", sino una invitación de infinita ternura en el ruego, que cuando tal ruego se oye, se recibe, se asume y se acepta, no se puede no responder más que afirmativamente a tan inefable súplica. Y frente a la discordancia entre el amado y la amada, tal ruego armoniza y equilibra el encuentro en una relación de amor. La discordancia entre ambos no cesa, pero la relación supra-racional del amor es capaz de convertir la carencia en desbordamiento y la súplica, en respuesta plena.

En definitiva, la antropología hermenéutica como proyecto total y en unidad en el pensador de Valence, aparece desplegada en sus rodeos sobre el ¿qué es el hombre? en $V I / H F$, y sobre el ¿quién es el hombre? y el "¿dónde estás?/heme aquí" en $S M A$, entre otros cuestionamientos y apelaciones supra-filosóficas de fe bíblica, evidenciando dicho recorrido un plus de sentido que desborda pre y supra-racionalmente, pre y meta-filosóficamente, el itinerario conceptual y judicativo sin más. Se trata de una nueva "lógica" que abre la comprensión del ser humano hacia una relación de preguntallamada-respuesta y de amor que excede, pero que, al mismo tiempo, asume como suelo y horizonte todo lenguaje filosófico, pregunta antropológica y exigencia última de sentido.

\section{Referencias}

Aranzueque, G. (Ed.). (1997). Horizontes del relato: lecturas y conversaciones con Paul Ricœur. Madrid: Universidad Autónoma de Madrid.

Blondel, M. (1973). L'Action (1893). Essai d'une critique de la vie et d'une science de la pratique. Paris: Presses Universitaires de France.

Borges, J.L. (1996). Obras Completas. Barcelona: Emecé.

Herrero Hernández, F.-J. (2005). De Husserl a Levinas. Un camino en la fenomenología. Salamanca: Publicaciones Universidad Pontificia. 
LAdrièRe, J. (1984). L'Articulation du sens: I. Discours scientifique et parole de la foi. Paris: Du Cerf.

LÉvinas, E. (2004). Autrement qu'être, ou au-delà de l'essence. Paris: Kluwer Academic.

Riceur, P. (2008). Amour et justice (AJ). Paris: Points.

Riceur, P. (1995). La Critique et la conviction. Entretien avec François Azouvi et Marc de Launay (CC). Paris: Calmann-Lévy.

Riceur, P. (1994). Fe y Filosofía. Problemas del lenguaje religioso (FF). Buenos Aires: Almagesto-Docencia.

Ricceur, P. (1992). Lectures 2. La contrée des philosophes (L2). Paris: Seuil.

Riceur, P. (1990). Soi-même comme un autre (SMA). Paris: Seuil.

Ricceur, P. (1989). Narrativité, phénoménologie et herméneutique. Encyclopédie Philosophique Universelle (pp. 63-71). Paris: PUF.

Riceur, P. (1986). Du Texte à l'action. Paris: Seuil.

Riceeur, P. (1985). Temps et récit: Le temps raconté. Paris: Seuil.

Riceeur, P. (1975). La Métaphore vive. Paris: Seuil.

Riceur, P. (1960). Philosophie de la volonté 2: Finitude et culpabilité (FC). Paris: Aubier.

Ricenur, P. (1950). Philosophie de la volonté 1: Le volontaire et l'involontaire $(V I)$. Paris: Aubier.

Tell M.B. (2014). Tras la huella del testimonio. Estudio filosófico sobre los silenciosos alcances de la antropología hermenéutica de Paul Riccur. Salamanca: Servicio de Publicaciones Universidad Pontificia de Salamanca). [En prensa].

Tell, M.B. (2013). Entre el «Toi, aime-moi!» y el «Me voici!». Develamiento y relación de las fuentes supra-filosóficas como claves para una renovada comprensión de la antropología filosófica de Paul Ricour. (Tesis No. 132.). Salamanca: Servicio de Publicaciones Universidad Pontificia de Salamanca.

Von Balthasar, H.U. (1999). Sólo el amor es digno de fe. (Trad. C. Vigil). Salamanca: Sígueme. 